\title{
Central Bank Communications and the General Public
}

\author{
By Andrew Haldane and Michael McMahon*
}

Blinder (2009, p. 26) wrote that "virtually all the research to date focuses on central bank communication with the financial markets. It may be time to pay some attention to communication with the general public." Almost ten years on, despite further rapid growth in central bank communication, it is unclear the general public have benefited. We first explore the growth of central bank communication and the reasons the public largely remain a blind spot (perhaps we should call it the "Blinder spot") for these communications. We then present the case for the desirability of greater communication with the public. We also explore the feasibility case for such communications using a recently-adopted innovation at the Bank of England. The main policy implication is that, while more still needs to be done, there are compelling reasons for central banks to continue trying.

\section{A Selective Revolution}

There has been an exponential growth increase in central bank communication over the past 70 years-a communications revolution (Haldane 2017 discusses various metrics of this). This revolution has been driven, in part, by the realization that communication can aid expectations, and hence, economic management (Blinder 2009).

\footnotetext{
* Haldane: Bank of England, Threadneedle Street, London, EC2R 8AH, UK (email: andy.haldane@bankofengland.co.uk); McMahon: University of Oxford, Manor Road Building, Oxford, OX1 3UQ, UK (email: michael.mcmahon@economics.ox.ac.uk). We thank Refet Grkaynak for his excellent discussion. We would also like to thank, for comments, discussion, and suggestions, David Bradnum, Shiv Chowla, Al Firrell, Stephen Hansen, David Nicholls, Chris Peacock, and Emma Rockall. The views expressed here do not necessarily represent the views of the Bank of England, the Monetary Policy Committee, Financial Policy Committee, or anyone else other than the authors. Any errors remain ours alone.

${ }^{\dagger}$ Go to https://doi.org/10.1257/pandp.20181082 to visit the article page for additional materials and author disclosure statement $(\mathrm{s})$.
}

There is a large body of academic evidence indicating that central bank communication is now itself a powerful lever of monetary policy; for instance, Gürkaynak, Sack, and Swanson (2005). But these studies have focused primarily on the effects of central bank communications on expectations derived from asset prices and professional forecasters. There is far less evidence that these communications have had any effect on the expectations and behavior of the general public; Binder (2017) is an exception. Moreover, there is little evidence to suggest this gap has narrowed in the last decade.

One reason for this is that central banks have often not made their main communications accessible to a sufficiently wide audience. Measured using a well-known measure of linguistic complexity, the Flesch-Kincaid reading grade score, typical central bank publications have reading grade levels of 14-18 (roughly equivalent to college-level). ${ }^{1}$ Given levels of literacy across the population, this would make them inaccessible to at least 90 percent of the general public. By contrast, political speeches are pitched at a high-school level (grade 8), reaching between a third and a half of the population.

Haldane (2017) stresses a deficit of public understanding as well as public trust in central banks-a twin deficits problem. Using the Bank of England's Inflation Attitudes Survey, a survey of around 2,000 individuals conducted since 2001, we construct a monetary policy "knowledge index" among the general public from responses to three questions about the institutional structure of monetary policy. This runs from a score of six ("perfect knowledge") to zero ("no knowledge").2

The mean overall knowledge score in the UK survey over the past 17 years has, at best, flat-lined. This suggests the public's

\footnotetext{
${ }^{1}$ Evidence for a selection of advanced economies is presented in Haldane (2017).

${ }^{2}$ Haldane and McMahon (2018) contains a full description of the analysis in this paper. See also Jost (2017).
} 
understanding of monetary policy structures appears to have been largely immune to central banks' communication revolution. Moreover, there is significant stratification in knowledge scores by age, education, and social class (as well as by income), with the young, less well-educated and poor being materially less knowledgeable. This suggests that central banks' current communications initiatives are by-passing large cohorts of society. Their communications revolution has been selective.

The survey also enables us to measure, as a proxy for trust, satisfaction with central banks' actions - 5 meaning most satisfied and 1 dissatisfied. As with trust measures from other surveys, this declined during and following the financial crisis and has yet to fully recover. This pattern in satisfaction or trust scores in central banks' actions has been broadly-based across demographic groups and across countries.

Facing these twin deficits, a number of central banks have recently acknowledged the need to adapt their communications strategies to improve their reach to the general public, including through more accessible language and more direct engagement (Haldane 2017). Because such efforts are not costless, however, two important considerations arise: feasibility and desirability.

\section{Desirability}

Perhaps talking directly to the public, regardless of its feasibility, is unnecessary. Hayek (1945) argues that market prices could communicate the necessary information. If so, the key is to ensure that experts and information intermediaries are able to understand and transmit the central banks' signals. In this section we discuss four reasons why it may be desirable to speak directly to a wider audience.

First, the Hayekian channel through financial prices is unlikely to work perfectly. Households' expectations and behavior are shaped by a large range of factors, other than asset prices. For example, Shiller (2017) stresses the important role that "popular narratives" can play in determining behavior in the macroeconomy; Bailey et al. (2017) discuss the role of social contagion in driving housing market behavior; and Mani et al. (2013) show how the stress induced by financial worries affects financial decisions. A better understanding of the factors driving the economy, and economic policy, could help to reduce the incidence of such self-reinforcing expectational swings in sentiment and behavior.

The epidemiology of narratives suggests that, to become convincing and credible, communications may need to be simple, relevant, and story-based. Typical central bank communications tend to fail on all three fronts. This probably explains why only technicians tend to listen to central bank messages (Blinder 2018). It also explains why the cost of capital channel may be at best partial, at worst ineffective, when it comes to influencing the general public.

Columns 1-3 of Table 1 show the relationship between our measures of monetary policy knowledge and satisfaction, and absolute values of deviations of household inflation expectations from the inflation target, controlling for time fixed-effects and various demographic factors. Households who report greater knowledge and greater satisfaction with monetary policy are also likely to have one-year, two-year, and five-year inflation expectations that are closer to the inflation target; this is similar to findings for the United States in Binder (2017). There is growing evidence that inflation expectations affect economic and financial choices made by households (Bachmann, Berg, and Sims 2015; Armantier et al. 2015; Malmendier and Nagel 2016).

Second, building public understanding may be important as a means of establishing trust and credibility about central banks and their policies. This is important not only for shaping expectations and behavior among households when meeting inflation targets. It is also important for reasons of political accountability, ensuring operationally independent central banks are meeting the terms of their social contract with wider society.

Column 4 of Table 1 shows that, allowing for various controls, satisfaction in central banks' actions is positively correlated with institutional understanding. It is also positively correlated with measures of central bank credibility (column 5). ${ }^{3}$ Taken together, this suggests that there is a common driving relationship between these

\footnotetext{
${ }^{3}$ In 2017, the survey also asked questions about credibility; for example, Q27-01 asks respondents to what extent they agree that the Bank of England is credible.
} 
Table 1-Regression Analysis of Inflation Attitudes Survey

\begin{tabular}{|c|c|c|c|c|c|}
\hline Main regressors: & $\begin{array}{c}\left|E_{t}\left[\pi_{t+1}\right]-\pi *\right| \\
\text { (1) }\end{array}$ & $\begin{array}{c}\left|E_{t}\left[\pi_{t+2}\right]-\pi *\right| \\
\text { (2) }\end{array}$ & $\begin{array}{c}\left|E_{t}\left[\pi_{t+5}\right]-\pi *\right| \\
\text { (3) }\end{array}$ & $\begin{array}{c}\text { Satisfaction } \\
\text { (4) }\end{array}$ & $\begin{array}{c}\text { Credibility } \\
\text { (5) }\end{array}$ \\
\hline Knowledge & $\begin{array}{c}-0.032 \\
{[0.00]}\end{array}$ & $\begin{array}{c}-0.068 \\
{[0.00]}\end{array}$ & $\begin{array}{c}-0.066 \\
{[0.00]}\end{array}$ & $\begin{array}{c}0.12 \\
{[0.00]}\end{array}$ & $\begin{array}{c}0.052 \\
{[0.00]}\end{array}$ \\
\hline Satisfaction & $\begin{array}{c}-0.14 \\
{[0.00]}\end{array}$ & $\begin{array}{c}-0.19 \\
{[0.00]}\end{array}$ & $\begin{array}{c}-0.22 \\
{[0.00]}\end{array}$ & & $\begin{array}{c}0.37 \\
{[0.00]}\end{array}$ \\
\hline Constant & $\begin{array}{c}1.80 \\
{[0.00]}\end{array}$ & $\begin{array}{c}2.80 \\
{[0.00]}\end{array}$ & $\begin{array}{c}3.11 \\
{[0.00]}\end{array}$ & $\begin{array}{c}2.92 \\
{[0.00]}\end{array}$ & $\begin{array}{c}2.04 \\
{[0.00]}\end{array}$ \\
\hline $\begin{array}{l}\text { Observations } \\
R^{2}\end{array}$ & $\begin{array}{c}52,146 \\
0.081\end{array}$ & $\begin{array}{c}24,168 \\
0.057\end{array}$ & $\begin{array}{c}21,533 \\
0.044\end{array}$ & $\begin{array}{c}58,730 \\
0.118\end{array}$ & $\begin{array}{l}3,382 \\
0.279\end{array}$ \\
\hline $\begin{array}{l}\text { Estimation } \\
\text { Demographic controls } \\
\text { Year fixed effects } \\
\text { Sample }\end{array}$ & $\begin{array}{c}\text { OLS } \\
\text { Yes } \\
\text { Yes } \\
2001-2017\end{array}$ & $\begin{array}{c}\text { OLS } \\
\text { Yes } \\
\text { Yes } \\
2009-2017\end{array}$ & $\begin{array}{c}\text { OLS } \\
\text { Yes } \\
\text { Yes } \\
\text { 2009-2017 }\end{array}$ & $\begin{array}{c}\text { OLS } \\
\text { Yes } \\
\text { Yes } \\
2001-2017\end{array}$ & $\begin{array}{l}\text { OLS } \\
\text { Yes } \\
\text { No } \\
2017\end{array}$ \\
\hline
\end{tabular}

Notes: Satisfaction measures respondent satisfaction with how the Bank is carrying out monetary policy to control inflation, Knowledge is their score in terms of understanding the institutions setting monetary policy, and $E_{t}\left[\pi_{t+h}\right]$ is the respondent's expectation for $h$-years ahead inflation where $h=1,2$, and 5. $p$-values constructed using robust standard errors are reported in brackets below the coefficient estimates. Demographic controls for gender, age, income, class, working status, housing tenure, education, and region are included.

three concepts. It may be that you cannot build one without the other. This justifies significant efforts, by the central bank and providers of education, to address the issue of economic understanding as a means of building trust and credibility.

Third, traditional information intermediaries, such as the mainstream media and financial markets, may benefit from new, simpler narrative communication. Finally, it is believed that Greek philosopher Epictetus said "We have two ears and one mouth so that we can listen twice as much as we speak." There may be a lesson here for central banks: to engage in more listening to messages from the general public, given that aggregating information is one of a monetary policy committees' key roles (Hansen, McMahon, and Velasco Rivera 2014).

\section{Feasibility}

If desirable, what can central banks do to reach those people currently bypassed by central bank communication? Many central banks are already engaged in efforts to expand their outreach, engagement, and education. Whether these new approaches will deliver significant gains remains to be seen. However desirable, Blinder (2018) is pessimistic that central banks are likely to land their messages with the general public.
We examine a recent communication initiative by the Bank of England. In November 2017 the Bank of England launched a new, broader-interest version of its quarterly Inflation Report (IR), augmented with new layers of content aimed explicitly at speaking to a less-specialist audience. This layered content was provided alongside the established (more technical) IR and Monetary Policy Summary. The layered content had a Flesch-Kincaid Grade Level of 7.8 (eighth grade level), which compares with the Monetary Policy Summary which had a Flesch-Kincaid Grade Level of 13.4.

We first assess message reach. The increased accessibility of the text should, in principle, improve the reach and penetration of the Bank's communication. We compare November 2017 (which saw the first rate rise in a decade) with the August 2017 IR and the August 2016 IR (the latter which was associated with a $25 \mathrm{bps}$ rate reduction and additional Quantitative Easing).

Overall, the analysis is a nuanced good news message. Website activity over the course of the 24 hours after the announcement increased markedly in November 2017, almost doubling compared with earlier IRs. Almost all of this increase was associated with hits on the new content. Numbers of tweets and retweets associated with the IR were materially higher than in August 2017, but slightly lower than in August 2016 (though the Bank itself issued more than 
twice as many tweets in August 2016 than in November 2017). One clear finding is that monetary policy news itself, rather than the means by which it is communicated, is the largest single factor determining the reach of Twitter activity. This makes detecting the impact of changes to communications strategy problematic using traffic data alone.

The Bank of England's Regional Agents also carried out a survey of their business contacts following release of the November IR, asking them specifically about the new layered content. More than 70 percent of respondents felt the new layered summary helped them to better understand the IR's messages. And around 60 percent of respondents felt the new communication improved their perceptions of the Bank. Although encouraging, these results should also be treated cautiously given the possibility of self-selection by companies and the absence of a direct comparison with the traditional IR.

\section{A. An Experiment with the New Layers}

We now assess the impact of the new Bank of England communications more directly through a controlled experiment. These experiments were conducted after the IR's release in November on two distinct samples. First, a survey of 285 members of the UK general public, recruited by a third-party company ("Public sample"). Second, a sample of first-year graduate students in the department of economics at the University of Oxford ("MPhil sample").

All participants were asked to outline their expectations for CPI inflation, unemployment, and interest rates over the next two years. These were provided on a five-point scale from "Fall significantly $(-2)$ " through "Broadly unchanged (0)" to "Increase significantly (2)." The IR projections can be mapped to this scale, enabling us to work out whether reading and believing the latest IR led participants to update their beliefs, and if their expectations had become more pessimistic (higher inflation, unemployment and/or interest rates) or optimistic.

Participants were then randomly assigned to read either the traditional Monetary Policy Summary that accompanies the IR or the new, simplified layered content. A dummy variable, $D$ (Layers), indicates those participants that read only the new content.
In order to assess the difference between the new and old communication strategies, participants then answered three questions:

(i) "To what extent are you able to understand the content and messages of the material you just read?" Answers yield a five-point numeric variable Understand which ranges from 1 ("None or nearly none of it") to 5 ("All or nearly all of it").

(ii) "How has reading the excerpt from the Inflation Report summary changed your views or expectations on the outlook for the UK economy, if at all?" We use answers to define a dummy variable $D$ (Adjust) which is 1 if the participant adjusts their expectations to be closer to the IR forecast.

(iii) "Learning that this is typical communication in the Bank of England's quarterly Inflation Report, how has the Inflation Report summary affected your perceptions of the Bank of England, if at all?" $\Delta$ Perception runs from "Worsened significantly (1)" through "Broadly unchanged (3)" to "Improved significantly (5)."

Table 2 presents the results of regressions of $D$ (Layers) on these three dependent variables from the two different samples. Columns 1-3 present the results for the public sample and 4-6 for the MPhil survey. We use a series of demographic controls in the public sample, though excluding controls does not affect the results. These controls are not available in the MPhil sample. There are three main results.

First, the results confirm that the new layered content is easier to read and understand, even for technically-advanced MPhil students. This improvement in understanding was statistically significant at the 1 percent level for both samples, and averaged 0.68 points across the two. To contextualize these benefits, the effect of the layered content in terms of greater public understanding $(+0.71)$ was larger than the effect on understanding of studying economics as part of a university degree $(+0.55)$. Since more technically-trained MPhil students found the material easier to understand, this suggests there 
TABle 2-Regression Analysis of Communication Experiment

\begin{tabular}{|c|c|c|c|c|c|c|}
\hline Main regressors: & $\begin{array}{l}\text { Understand } \\
\text { (1) }\end{array}$ & $\begin{array}{c}\Delta \text { Perception } \\
\text { (2) }\end{array}$ & $\begin{array}{c}\mathrm{D} \text { (Adjust) } \\
(3)\end{array}$ & $\begin{array}{l}\text { Understand } \\
\text { (4) }\end{array}$ & $\begin{array}{c}\Delta \text { Perception } \\
(5)\end{array}$ & $\begin{array}{c}\mathrm{D} \text { (Adjust) } \\
(6)\end{array}$ \\
\hline D(Layers) & $\begin{array}{c}0.71 \\
{[0.00]}\end{array}$ & $\begin{array}{c}0.083 \\
{[0.33]}\end{array}$ & $\begin{array}{c}0.35 \\
{[0.04]}\end{array}$ & $\begin{array}{c}0.63 \\
{[0.00]}\end{array}$ & $\begin{array}{c}0.35 \\
{[0.01]}\end{array}$ & $\begin{array}{l}0.090 \\
{[0.78]}\end{array}$ \\
\hline $\mathrm{D}($ Economics $)$ & $\begin{array}{c}0.54 \\
{[0.00]}\end{array}$ & $\begin{array}{c}-0.032 \\
{[0.76]}\end{array}$ & $\begin{array}{c}-0.24 \\
{[0.32]}\end{array}$ & & & \\
\hline BoE confidence & $\begin{array}{c}0.10 \\
{[0.10]}\end{array}$ & $\begin{array}{c}0.15 \\
{[0.00]}\end{array}$ & $\begin{array}{c}-0.11 \\
{[0.28]}\end{array}$ & $\begin{array}{c}0.16 \\
{[0.29]}\end{array}$ & $\begin{array}{c}-0.14 \\
{[0.19]}\end{array}$ & $\begin{array}{c}0.28 \\
{[0.26]}\end{array}$ \\
\hline Constant & $\begin{array}{c}2.68 \\
{[0.00]}\end{array}$ & $\begin{array}{c}3.19 \\
{[0.00]}\end{array}$ & $\begin{array}{c}-0.21 \\
{[0.52]}\end{array}$ & $\begin{array}{c}3.63 \\
{[0.00]}\end{array}$ & $\begin{array}{c}3.12 \\
{[0.00]}\end{array}$ & $\begin{array}{c}-0.81 \\
{[0.01]}\end{array}$ \\
\hline $\begin{array}{l}\text { Observations } \\
R^{2}\end{array}$ & $\begin{array}{c}285 \\
0.226\end{array}$ & $\begin{array}{c}285 \\
0.055\end{array}$ & 285 & $\begin{array}{c}68 \\
0.140\end{array}$ & $\begin{array}{c}66 \\
0.111\end{array}$ & 68 \\
\hline $\begin{array}{l}\text { Estimation } \\
\text { Demographic controls } \\
\text { Sample }\end{array}$ & $\begin{array}{l}\text { OLS } \\
\text { Yes } \\
\text { Public }\end{array}$ & $\begin{array}{l}\text { OLS } \\
\text { Yes } \\
\text { Public }\end{array}$ & $\begin{array}{l}\text { Probit } \\
\text { Yes } \\
\text { Public }\end{array}$ & $\begin{array}{l}\text { OLS } \\
\text { No } \\
\text { MPhil }\end{array}$ & $\begin{array}{l}\text { OLS } \\
\text { No } \\
\text { MPhil }\end{array}$ & $\begin{array}{l}\text { Probit } \\
\text { No } \\
\text { MPhil }\end{array}$ \\
\hline
\end{tabular}

Notes: $\mathrm{D}$ (Layers) is one if the participant was randomly assigned the new, layered content in the experiment. $\mathrm{D}$ (Economics) is a dummy variable which is one if the participant has studied economics as part of a university degree course. BoE Confidence is a numeric variable rating the participant's confidence in the Bank. Demographic controls, available only for the public survey, are separate dummy variables equal to one indicating the respondent is female, English-speaking, British nationality, student or full-time employed. $p$-values constructed using robust standard errors are reported in brackets below the coefficient estimates.

are benefits to clarifying and simplifying central bank messages even to traditional audiences.

Second, those that read the new layered content tended to develop an improved perception of the institution. While this is not statistically significant in the public survey, it is highly significant in the MPhil sample. This may suggest that the general public often require more convincing to change their perceptions of public institutions.

Finally, columns 3 and 6 report the results of estimating a probit model to determine whether the layered content helps people to update their projections and whether these revised projections are then more in line with the Bank's main forecast messages. In the case of the general public survey, we find that more straightforward communication boosts the chances that the participant's beliefs move more closely into alignment with the Bank's forecasts. For MPhil students, the coefficient is also positive but not statistically significant.

\section{Research and Policy Implications}

With research on the impact of central bank communications on the general public still in its infancy, further research would be valuable to establish the benefits and feasibility of such strategies. This might draw on new or existing surveys of the public, alongside controlled experiments to measure the marginal contribution of changes to the style and strategy of central bank communications.

On a practical level, central banks aiming to reach a broader audience will need to continue to innovate and experiment with different methods and media for engaging the general public. This will, inevitably, require a degree of trial and error, including learning lessons from other areas of public policy charged with communicating messages to the wider public. Success should be measured, not by the ability to reach everyone, but rather to influence beyond the small minority of technical specialists and information intermediaries who currently form the core of central banks' audiences.

\section{REFERENCES}

Armantier, Olivier, Wändi Bruine de Bruin, Giorgio Topa, Wilbert van der Klaauw, and Basit Zafar. 2015. "Inflation Expectations and Behavior: Do Survey Respondents Act on Their Beliefs?" International Economic Review 56 (2): 505-36.

-Bachmann, Rüdiger, Tim O. Berg, and Eric 
R. Sims. 2015. "Inflation Expectations and Readiness to Spend: Cross-Sectional Evidence." American Economic Journal: Economic Policy 7 (1): 1-35.

Bailey, Michael, Rachel Cao, Theresa Kuchler, Johannes Stroebel. 2017. "The Economic Effects of Social Networks: Evidence from the Housing Market." Unpublished.

Binder, Carola. 2017. "Fed Speak on Main Street: Central Bank Communication and Household Expectations." Journal of Macroeconomics 52: 238-51.

Blinder, Alan. 2009. "Talking about Monetary Policy: The Virtues (and Vices?) of Central Bank Communication." Bank for International Settlements Working Paper 274.

Blinder, Alan S. 2018. "Through a Crystal Ball Darkly: The Future of Monetary Policy Communication." AEA Papers and Proceedings. https://doi.org/10.1257/pandp.20181080.

Gürkaynak, Refet S., Brian Sack, and Eric T. Swanson. 2005. "Do Actions Speak Louder Than Words? The Response of Asset Prices to Monetary Policy Actions and Statements." International Journal of Central Banking 1 (1): 55-93.

Haldane, Andrew. 2017. "A Little More
Conversation A Little Less Action.” Paper presented at the Federal Reserve Bank of San Francisco, Macroeconomics and Monetary Policy Conference, San Francisco, CA.

Haldane, Andrew, and Michael McMahon. 2018. “Central Banks' Blind(er) Spot." Unpublished.

Hansen, Stephen, Michael McMahon, and Carlos Velasco Rivera. 2014. "Preferences or Private Assessments on a Monetary Policy Committee?" Journal of Monetary Economics 67 (C): $16-32$.

Hayek, F. A. 1945. "The Use of Knowledge in Society." American Economic Review 35 (4): 519-30.

Jost, Adriel. 2017. "Is Monetary Policy Too Complex for the Public? Evidence from the UK." Swiss National Bank Working Paper 2017-15.

Malmendier, Ulrike, and Stefan Nagel. 2016. "Learning from Inflation Experiences." Quarterly Journal of Economics 131 (1): 53-87.

Mani, Anandi, Sendhil Mullainathan, Eldar Shafir, and Jiaying Zhao. 2013. "Poverty Impedes Cognitive Function." Science 341 (6149): 976-80.

-Shiller, Robert J. 2017. "Narrative Economics." American Economic Review 107 (4): 9671004. 